\title{
PARMENIDES: Facilitating Deliberation in Democracies
}

\author{
KATIE ATKINSON, TREVOR BENCH-CAPON and PETER \\ MCBURNEY \\ Department of Computer Science, University of Liverpool, Chadwick Building, Peach Street, \\ Liverpool, L69 7ZF, United Kingdom \\ (E-mail:katie@csc.liv.ac.uk)
}

\begin{abstract}
Governments and other groups interested in the views of citizens require the means to present justifications of proposed actions, and the means to solicit public opinion concerning these justifications. Although Internet technologies provide the means for such dialogues, system designers usually face a choice between allowing unstructured dialogues, through, for example, bulletin boards, or requiring citizens to acquire a knowledge of some argumentation schema or theory, as in, for example, ZENO. Both of these options present usability problems. In this paper, we describe an implemented system called PARMENIDES which allows structured argument over a proposed course of action, without requiring knowledge of the underlying argumentation theory.
\end{abstract}

Key words: deliberative democracy, argumentation, practical reasoning

\section{Introduction}

What precisely do we mean by "democracy"? Political philosophers have attempted to answer this question by articulating normative models of democracy, and we begin our paper with a brief description of the three most influential of these. The problem they each confront was first formulated in an abstract form by philosopher Rousseau (1994), who viewed a polity as comprising just two entities: Society and the State. Society is the collection of individuals, organizations and companies in a polity, together with the panoply of relationships between them, while the State is the apparatus of public-sector administration. The fundamental question considered by political theorists is then: What should be the process of formation of political will? or How should Society program the State? Supporters of democracy believe that these questions should be answered with the use of democratic procedures, such as elections based on universal adult suffrage. But if such procedures are used, what is the nature of the relationship between citizens and their elected representatives? Rousseau had assumed that the people have 
a single "general will" which their elected representatives should seek to implement, but this is at best only a high-level approximation to the multifarious cacophony which is modern democracy.

The first modern political theory of democracy which sought to answer this fundamental question was proposed in 1942 by Austrian-American economist Schumpeter (1950). Schumpeter's theory, possibly in reaction to the mass populism of Nazism and Communism and to his own failed political career, was disdainful of ordinary people and their views: "Thus the typical citizen drops down to a lower level of mental performance as soon as he enters the political field. He argues and analyses in a way which he would readily recognize as infantile within the sphere of his real interests. He becomes a primitive again." (Schumpeter 1950, p. 262). Consequently, Schumpeter proposed that elected officials should act as a technocratic elite, making decisions on behalf of the general public and in accordance with what the elite believes are the public's best interests. Apart from voting, the people are entirely passive in Schumpeter's model of democracy, which has rightly acquired the label elitist (Bohman and Rehg, p. x). In other work, one of us called this the Wise Elite Model of democracy (McBurney and Parsons 2004).

In contrast to Schumpeter's hierarchical view of democracy, Anthony Downs proposed an economic-theoretic model of political will-formation in a democracy in which citizens were more than simply passive objects (Downs 1957). This model has since been called a rational-choice or liberal model (Habermas 1998), and it views democracy as akin to the operation of an economic marketplace. Downs proposed a theory of democracy where political parties and interest groups act as entrepreneurs, offering alternative "products" in the form of bundles of state-instructions (or equivalently, ideologies, which are philosophies of bundle-formation), to voters who then "purchase" their preferred bundle when they vote. That bundle with the greatest "market-share" - in the form of popular votes - becomes the set of instructions used to program the State. Downs explicitly assumed that voterconsumers in a free and democratic society make their political choices on the basis of their perceived self-interest, and act according to the now-standard definition of rational economic behavior, e.g. (Arrow 1951). In other words, voters are assumed to always vote so as to maximize their perceived expected utility from the outcome of the election. In addition to consuming bundles of state-instructions, citizens also consume information about policies, ideologies, political parties and candidates to the extent necessary to make their voting decisions. And, as for any other good, such consumption may be subject to time-, resource-, or processing-constraints, and cost-benefit tradeoffs.

The rational-choice model affords citizens a greater role than does the wise elite model, namely the role of consumers of relevant political information and policies. But citizens, in the rational-choice model of democracy, are not 
regarded as producers of political information or public policies. In contrast, the deliberative democracy model of political will-formation views citizens also as producers of political information and policies, because they participate in political processes and debate, identify and publicize issues of personal or social concern, exchange arguments for and against various policy options, and generally seek to influence the outcomes of political decision processes (Bessette 1980; Bohman and Rehg 1997). Seeking to influence and persuade other participants means that reasonable citizens will themselves be open to persuasion, and thus potentially undergo what has been called selftransformation (Forester 1999, p. 184). As Frank Michelman wrote: "Deliberation ... refers to a certain attitude toward social cooperation, namely, that of openness to persuasion by reasons referring to the claims of others as well as one's own. The deliberative medium is a good faith exchange of views - including participants' reports of their own understanding of their respective vital interests $-\ldots$ in which a vote, if any vote is taken, represents a pooling of judgments" (Michelman 1989, p. 293).

These three models of political will-formation in a democracy can be seen as offering alternative roles to the citizens who comprise the Society. In the Wise Elite model, the people are seen as completely passive, except when choosing the Elite. In the Rational-Choice model, the people are viewed as consumers of policies, ideologies and information. In the Deliberative model, the people are viewed as both consumers and producers of policies, ideologies and political information. As one may expect, citizens and politicians typically have different views about which model is preferred (Sæbø and Nilsen 2004), for example, offers empirical evidence that politicians prefer the elitist model and active citizens the deliberative model. Despite this difference, there is some evidence that deliberative decision-processes lead to better decision outcomes (Fiorino 1989; Webler et al. 2001).

The last two decades have seen a deliberative turn in the study of democracy in political philosophy. Thus, in this view, democracy is not simply a matter of periodic voting: it should also engage its members in informed debate about issues of concern. In a democracy, governments should not only be accountable for the decisions they take, but should justify these decisions in full awareness of, and in response to, the wishes and convictions of the people they govern. Such justification, of course, requires communication between the government and the people. Today, with the opportunities provided by the World Wide Web, communication is physically easier than ever before, but the long-standing problems that bedevil the effectiveness of communication remain. To be effective, communication must be clear, unambiguous and structured so that misunderstandings are minimized. In (Greenwood et al. 2003a) we proposed a structure for persuasive argument that was intended to ease these communication problems, and to promote informed debate. 
In this paper, we describe a computer program which exploits this structure, and illustrate it with an example. Our work complements recent research on the application of information technologies to support democratic participation and debate. Systems such as ZENO (Gordon and Karacapilidis 1997) and DEMOS (Lührs et al. 2003) aim to assist citizens to communicate with one another and with public officials over matters of community concern and to do so in a dialogue possibly involving multiple simultaneous parties. Likewise, the intelligent systems proposed in McBurney and Parsons (2001) for public discussion as part of decision-making on environmental and health regulations are also intended for multi-party dialogues. By contrast, the system proposed in this paper, as with our earlier work (Greenwood et al. 2003a), is intended for dialogues involving only two simultaneous parties. However, all these systems seek to embody deliberative notions of democracy and to support public participation in decision-making (Gordon and Richter 2002). Our model also supports the preferred model of both politicians and their constituents. It allows for the presentation and justification of the initial policy by the politicians, whilst encouraging their constituents to critique it and to propose amendments and alternatives.

\section{Structure for debate}

We start from an assumption that one party (say, the Government) has proposed an action or course of action, and presents a justification for this proposal to the other party, who may respond. The structure for the interaction between the two parties involves:

- A clear statement of the justification for an action, which makes explicit all the components of the reasoning underlying the argument;

- An opportunity to challenge any of the components and any of the inferential links between them;

- An opportunity to propose alternative actions and justifications.

Within this dialogue structure, we see the justification for an action as involving the following argument scheme (AS1):

- An understanding of the current situation;

- A view of the situation which will result from performance of the action;

- Features of the new situation which are considered desirable (the aspects which the action was performed in order to realize);

- The social goals which are promoted by these features (the reasons why they are desirable).

In (Greenwood et al. 2003b), we advanced this structure for discussion and identified a number of ways in which it could be attacked. There, we 
identified 15 distinct types of attack, several of which had a number of variants according to the extent to which the attacker advanced a positive position in reply. Table I shows the attacks and the number of variants.

Given that we can distinguish no fewer than 34 ways in which a position may be attacked, and that in practice an attack on a position may combine several of these attacks, we can already see that there is much scope for misunderstanding the precise nature of an attack, and considerable difficulty in giving a clear, unambiguous statement of the attack. It is this which causes many of the problems in communication of views when using traditional means of correspondence, such as letter, telephone or e-mail.

Our original intention (Greenwood et al. 2003a) was to implement a program controlling a computer mediated dialogue, in which the locutions would represent moves implementing the above attacks: this would ensure that each move was unambiguously identified with its intended effect. This program has been successfully implemented in JAVA, but evaluation has shown that, for casual users, many problems remain. Selecting the correct moves to realize a desired attack on a position is a task almost as difficult as correctly phrasing an attack in natural language. Essentially there is too much freedom of expression provided, and hence an overwhelming variety of options to select between. For this reason we have decided that if support is

Table I. Table of attractive

\begin{tabular}{|c|c|c|}
\hline Attack & Variants & Description \\
\hline 1 & 2 & Disagree with the description of the current situation \\
\hline 2 & 7 & Disagree with the consequences of the proposed action \\
\hline 3 & 6 & Disagree that the desired features are part of the consequences \\
\hline 4 & 4 & Disagree that these features promote the desired value \\
\hline 5 & 1 & Believe the consequences can be realized by some alternative action \\
\hline 6 & 1 & $\begin{array}{l}\text { Believe the desired features can be realized through } \\
\text { some alternative action }\end{array}$ \\
\hline 7 & 1 & Believe that an alternative action realizes the desired value \\
\hline 8 & 1 & $\begin{array}{l}\text { Believe the action has undesirable side effects which demote } \\
\text { the desired value }\end{array}$ \\
\hline 9 & 1 & $\begin{array}{l}\text { Believe the action has undesirable side effects which demote some } \\
\text { other value }\end{array}$ \\
\hline 10 & 2 & Agree that the action should be performed, but for different reasons \\
\hline 11 & 3 & Believe the action will preclude some more desirable action \\
\hline 12 & 1 & Believe the action is impossible \\
\hline 13 & 2 & Believe the circumstances or consequences as described are not possible \\
\hline 14 & 1 & Believe the desired features cannot be realized \\
\hline 15 & 1 & Disagree that the desired value is worth promoting \\
\hline
\end{tabular}


to be given to enable the general public to express their views as cogently as possible, some simpler form of interaction is required. These are exactly the problems encountered by earlier systems which have attempted to support democratic debate and dialogue, such as ZENO (Gordon et al. 1997) and TDG (Bench-Capon 1998). We address these usability problems by leading the user through a set sequence of moves representing a sensible interaction; by constraining the choice of the user, the need for the user to understand the underlying model so as to make informed selection of moves is removed. Additionally, wherever possible, statements are presented for approval or disapproval, reducing the problems associated with expressing the content of the various locutions. PARMENIDES is intended to realize these objectives.

The idea is to provide a simple web based interface which will guide the user in a structured fashion through a justification of an action giving opportunities to disagree at selected points. Each of these disagreements will represent one of the attacks above, so that the exact nature of the disagreement can be unambiguously identified by the system. The user's responses are written to a database so that information as to which points of the argument are more strongly supported than others can be gathered. Once the original position has been subjected to this critique, another sequence enables users to propose positions of their own, again in a way which will lead them to construct their position in the form of the argument scheme AS1.

In the next section we will describe PARMENIDES (Persuasive ARguMENt In DEmocracieS), using an example based on the 2003 debate as to whether the UK should go to war with Iraq (set before Iraq was invaded). This was perhaps one of the most widely debated issues of recent years, and disagreement as to the motives and justification of the action taken remains to this day.

\section{Navigation of PARMENIDES}

PARMENIDES is implemented using PHP scripts and provides a highly usable program accessible through any standard web browser. The system can be used at http://www.csc.liv.ac.uk/ katie/Parmenides.html

The aim of PARMENIDES is to present users with a position justifying a particular action and give them the opportunity to critique that position by disputing various points. We do not realize all of the attacks identified in Table I. Some of those attacks are directed against the soundness of the argument, and we here rely on the proponent of the position to produce only well formed arguments. Thus attacks 12,13 and 14 are considered unnecessary, since we assume that the states of affairs and actions described are possible. Similarly we ignore attack 3 : whether the features are entailed by the consequences is a matter of logic, and we rely on the proponent to produce a sound position. Attacks 6, 7, 9 and 11 involve the proposal of some counter position: 
these are addressed by providing facilities to allow the statement of alternative positions, as described in Section 3.2. Finally we ignore attack 10: this is a subtle matter relating to the motive for an action and is required in some domains, but since it does not vitiate the proposed action we do not use it here.

This leaves six attacks which we wish to solicit. This is effected through the navigation of a series of forms. After an introductory screen, Figure 1, which takes some information about the user and provides some explanation about the purpose and use of the system, the user is presented with a structured statement of the position to be considered, shown in Figure 2. We believe that because the statement follows AS1 it constrains the provider of the statement to be entirely explicit as to the nature of the argument and the purposes which justify the proposed argument. Note that on this screen, the text which can be agreed or disagreed with is highlighted in white and provides a link to a short justification for the statement. Thus if Human Rights is clicked, a justification of the UK's commitment to the promotion of human rights will be displayed. At this point users can simply accept the argument, in which case they are sent to a farewell screen. If, however, they wish to challenge the argument, they are sent to a screen concerning values, Figure 3, which begins their critique.

\subsection{CRITIQUING THE POSITION}

The users can now critique the initial position, starting with the opportunity to make attack 15 , registering disagreement with the social purposes under-

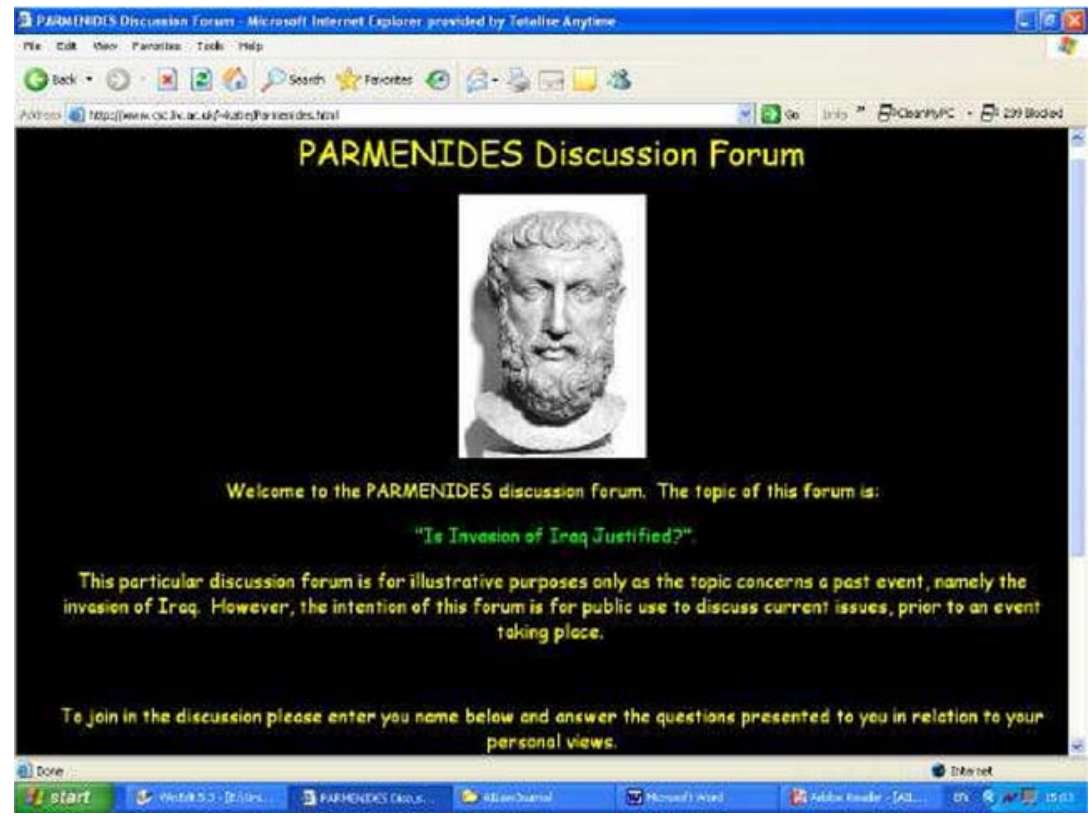

Figure 1. Introductory screen. 


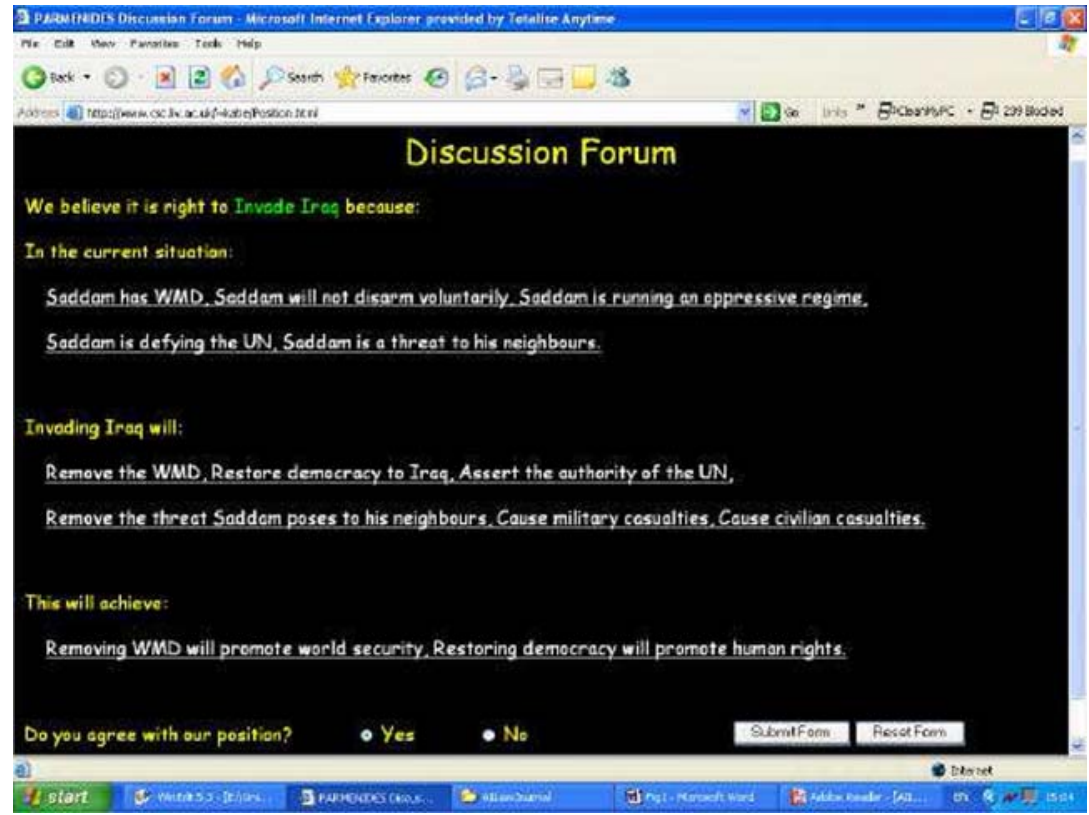

Figure 2. Statement of position.

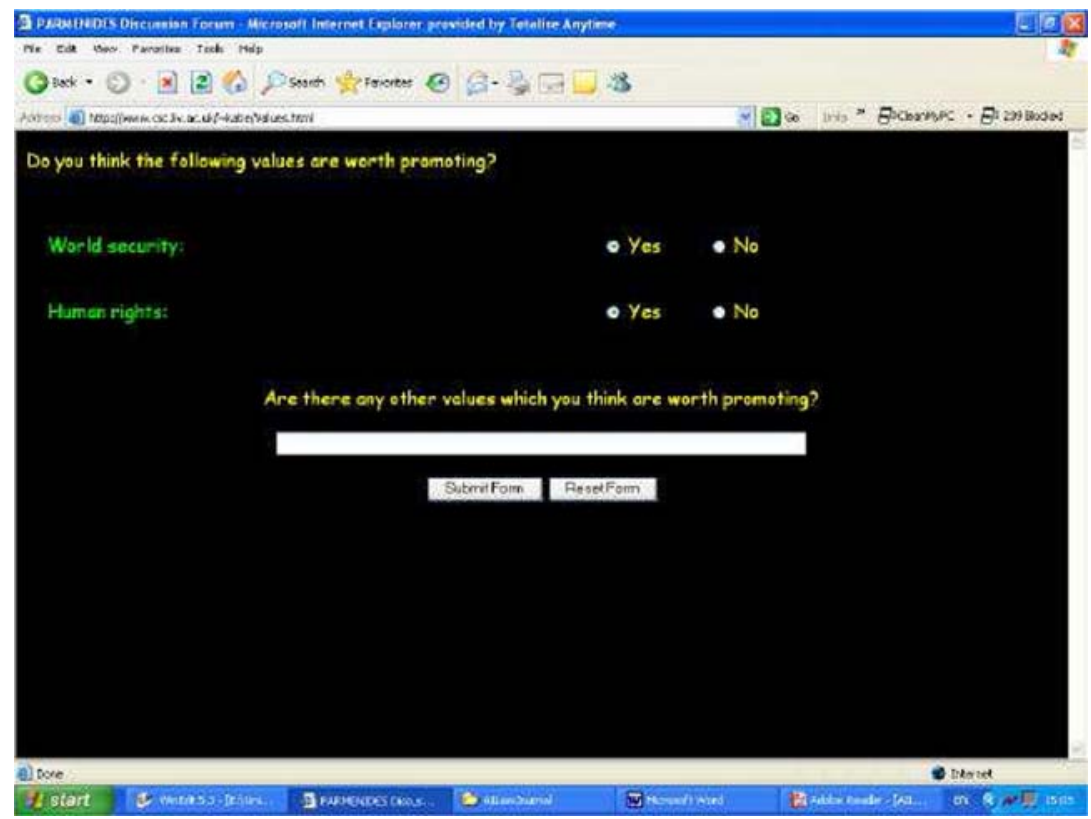

Figure 3. Screen presenting social values.

pinning the argument. If the user rejects all such values, further debate is fruitless, since there is insufficient common ground, and the exit screen is reached. Assuming that there is at least one value in common, however, they 
will go to a screen which allows them to state whether they believe these values are indeed promoted by the desired consequences of the proposed action (attack 4), with the screen being similar to the one shown subsequently in Figure 4. Here they also have the opportunity to state consequences of the action which they believe compromise the desired value (attack 8).

Following this screen the user is invited to agree or disagree that the proposed action will have the consequences envisaged by the proponent. This enables attack 2 and this screen is shown in Figure 4. Note that this screen gives the user the chance to check a 'Not applicable' option box for each statement. This is included to recognize the fact that the user may not be able to agree or disagree with the statements if they are based upon presuppositions that the user does not accept in the first place. For example, the first statement invites the user to say whether they agree or disagree that invading Iraq will remove the WMD. However, if they do not believe that Iraq has possession of WMD at all then they can choose the 'Not applicable' option. In a later screen the user's opinions about such presumptions will be elicited, but by including the 'Not applicable' option here we take into account that the questions currently being posed may be based upon these as yet unchallenged presuppositions.

Next the user is invited to suggest alternative actions to realize the desired consequences (attack 5), with the screen being similar to Figure 3. Finally they are invited to say whether they agree or disagree with the description of

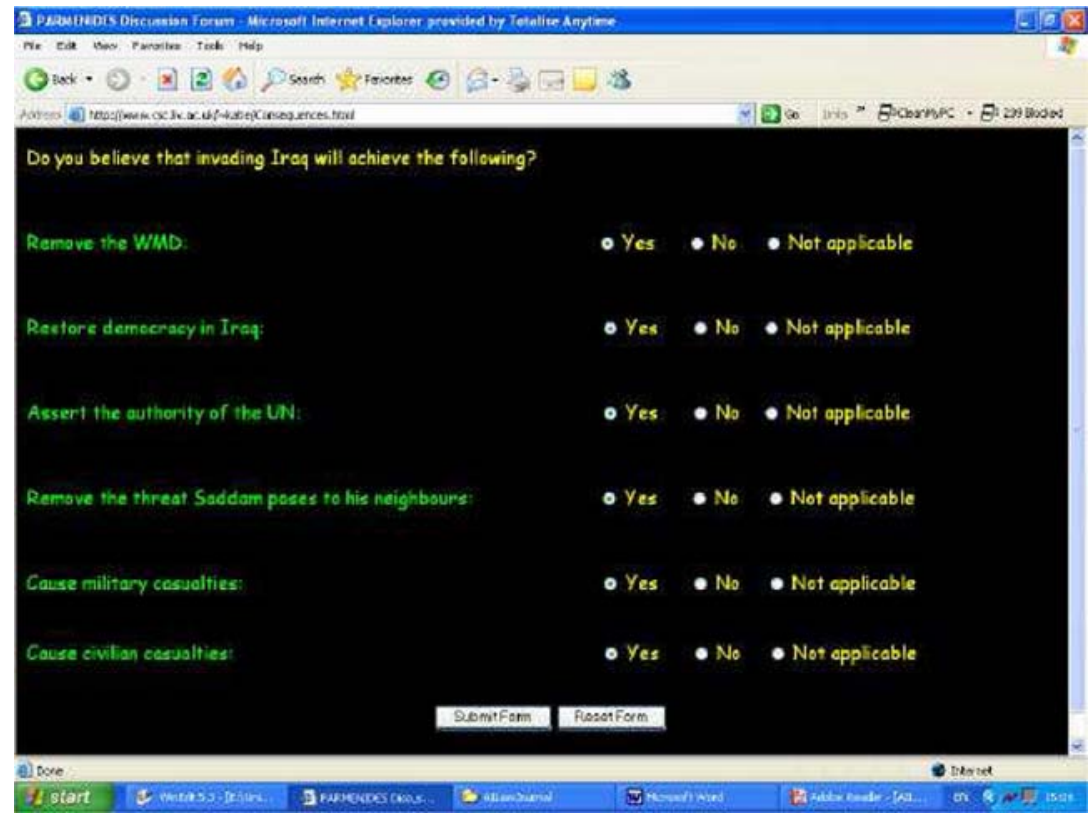

Figure 4. Links between action and consequences. 
the current situation (attack 1) and this screen is again similar to that shown in Figure 4. The user is then taken to the summary screen which thanks them for using the system and displays the responses that they have given, as partially shown in Figure 5.

\subsection{CONSTRUCTING AN ALTERNATIVE POSITION}

Now that the users have supplied all the answers to the questions posed regarding the initial justification for action they were presented with, they are invited to construct their own position regarding the topic in question. However, they may be satisfied with the answers already supplied when critiquing the original argument and, if this is the case, they may simply choose to exit the system whereupon they will simply be thanked for their input. But, if users do wish to construct their own position on the topic then they are given the opportunity, as shown in Figure 5, to follow a link which takes them to a page providing an explanation of the next step. This page explains how their views on the issue will be gathered to construct a justification of an action of the same structure that they were originally presented with upon entering PARMENIDES. Next the users are led to a screen which allows them to enter up to six relevant facts about the current state of affairs

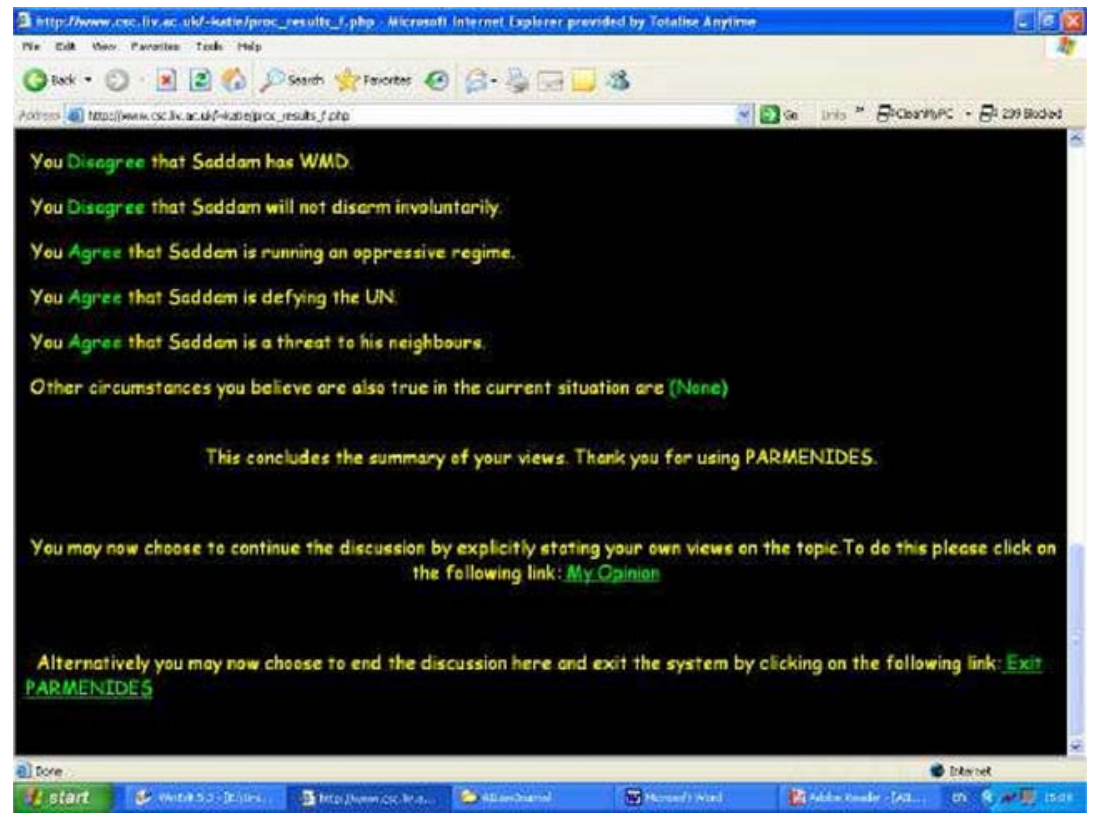

Figure 5. Summary screen displaying some of the user's responses and giving them an opportunity to continue or exit the system. 
in Iraq and this screen is shown in Figure 6. Based upon these circumstances, they are then taken to a screen which asks them to state what action they believe should be taken, as shown in Figure 7. Following on from this they are asked to input up to six consequences that they believe will follow from executing their specified action using a screen similar to that shown as Figure 6. Finally, another similar screen asks them to enter up to six reasons they believe that the consequences they specified are desirable. All the required questions needed to construct a new position have now been posed so the user is presented with a final screen giving him a summary of the answers he supplied. A partial view of this screen is shown in Figure 8. However, it may be the case that the user believes that there are multiple actions which can be executed in the circumstances he specified. If this is the case, then at end of the summary screen he can choose to enter another action, whereby he is taken back to the screen presented in Figure 7 and led through the same steps as before until he reaches the summary screen again. This step can be repeated as many times as is required until the user has input all actions, (plus following consequences and reasons) he believes to be desirable in the circumstances he stated. Alternatively, the user may be satisfied that he has submitted his full opinion and, if and when this is case, he can choose to exit the system whereupon he is presented with a final screen. This screen simply thanks him for using the system and then gives him the chance to re-enter PARMENIDES from the start.

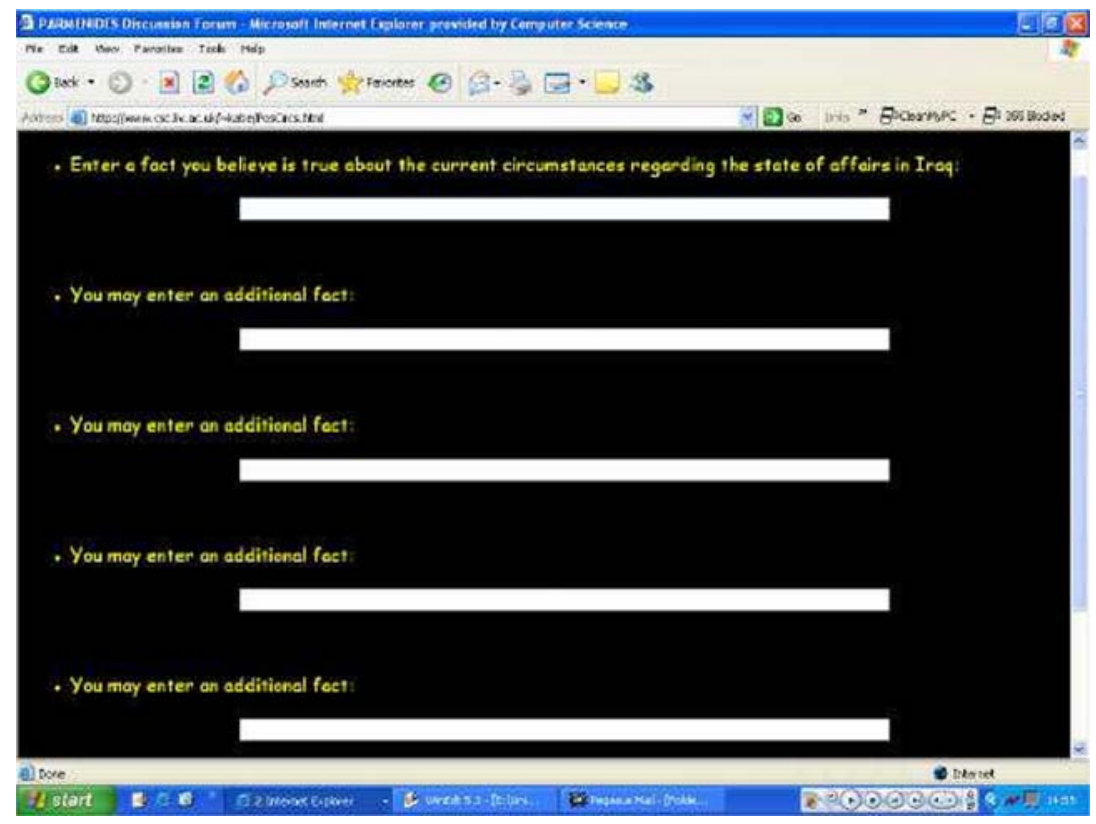

Figure 6. Screen asking about relevant circumstances. 


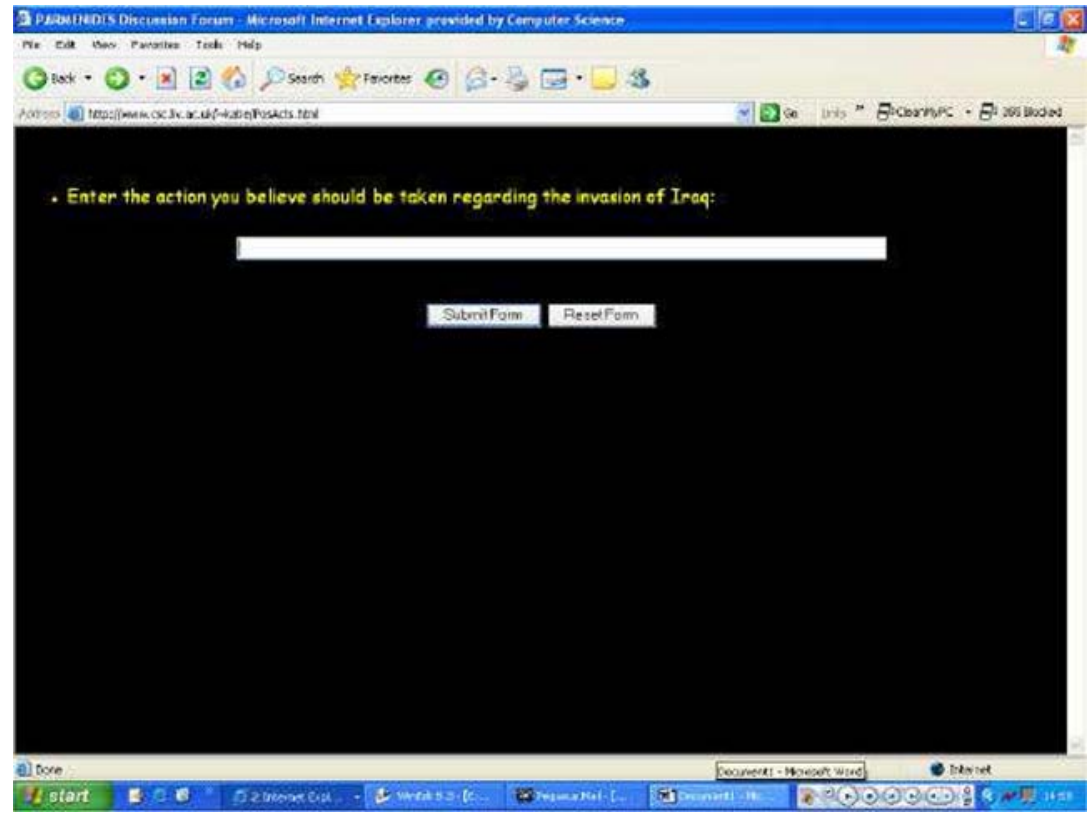

Figure 7. Screen enquiring what action should be taken.

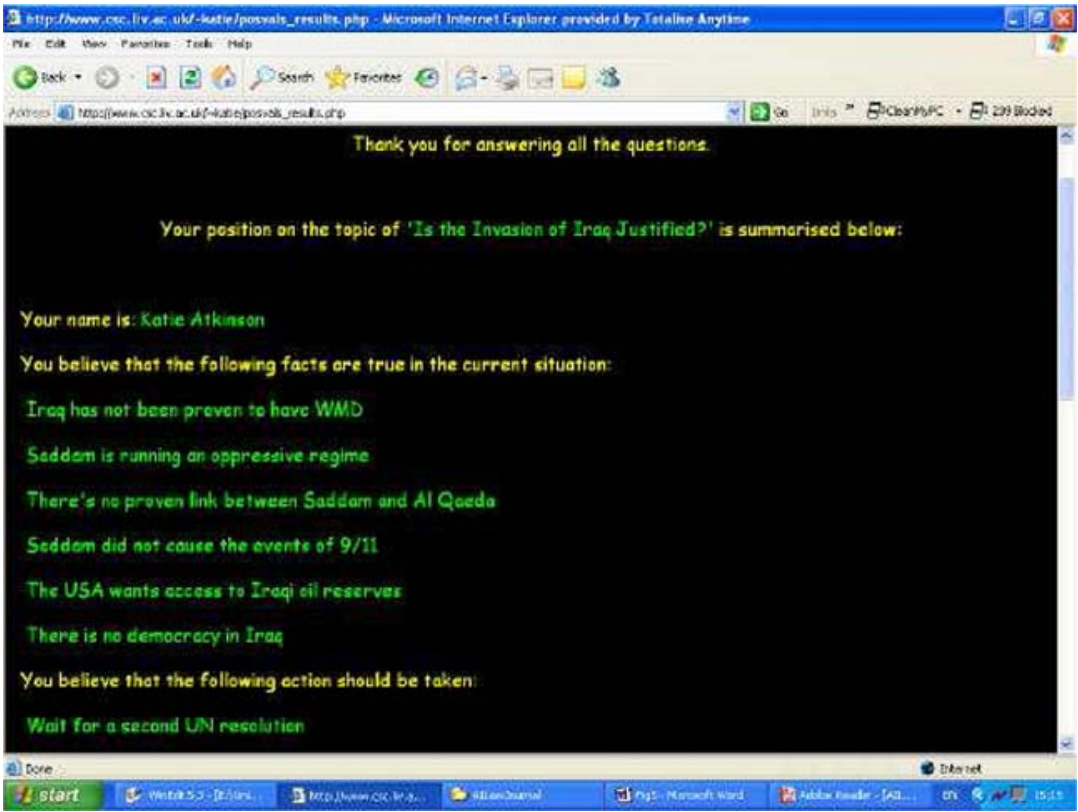

Figure 8. Screen giving summary of user's answers into a position stating the justification of his proposed action. 


\section{Discussion}

The critique in Section 3.1 realizes 6 of the 15 attacks possible against a position listed in Section 2. Each of these attacks proposes no positive information, and thus represents the simplest variant where several variants are possible. Taken together, the six attacks represent a full critique of the position proposed: if none of them can be made, then, provided the position is well formed, the position does indeed represent a justification of the proposed action. Of the nine attacks not provided during this sequence, four challenge the well formedness of the position (which we assume to be in order here), and, apart from the special case of attack 10, which does not dispute the action, the remaining attacks contest the action by developing a justification of an alternative action. The second sequence of screens, allow users to develop such alternative positions, as described in Section 3.2.

We are satisfied that PARMENIDES is usable by its target audience, and that it can effectively identify points of disagreement, and record them so that weight of opinion on various issues can be gauged. This is achieved without requiring the user of the system to have any particular familiarity with the underlying model of argument: the attacks are constructed from simple responses without any need for attacks to be explicitly formulated. Using PARMENIDES we can examine the acceptability of various parts of the position. For example, we are able to discriminate between those who support invasion for regime change from those who are concerned with international security. We can distinguish between those who believe that Saddam has no weapons of mass destruction from those who believe that he will disarm without invasion, from those who do not believe that he will use them. From this kind of information it is possible for the proponents of the policy to see which elements of the argument need to be put more persuasively or better justified, and which elements could be emphasized to increase the acceptability of the argument.

The free text elements entered by the user are intended to be considered by a moderator who can consider whether they need to be added to the position. Thus if sufficient respondents see some particular circumstance as relevant it can be added to the list of circumstances displayed: if it is not believed by the moderator this is expressed by giving false as its default. Similarly the moderator can examine the proposals for alternatives, and gauge which of these alternatives command substantial support, and the reasons for this.

We have envisaged use of PARMENIDES by the Government to justify its policy. A similar system could, however, be used by other bodies, such as pressure groups, who could subject their own positions to similar public scrutiny, and solicit additional arguments from the public. 
In this paper we have described PARMENIDES, a program which facilitates democratic debate by allowing people to critique a position justifying a particular intended action and to propose alternative positions in a way which while entirely straightforward to use, is capable of precisely identifying the points of disagreement with reference to a particular argumentation scheme, AS1. The key advantage of PARMENIDES is that while it is firmly grounded on a model of argument, it does not require the user to understand and use that model; it therefore avoids the many usability problems encountered by previous systems with a similar ambition.

\section{Acknowledgments}

We are grateful to Sam Atkinson for his invaluable help in implementing PARMENIDES. A shorter version of this paper was presented at EGOVERNMENT 2004 conference (Zaragoza, Spain, September 2004) and we are grateful to the anonymous reviewers and to the conference audience for their comments. Katie Atkinson is grateful for support from the UK Engineering and Physical Sciences Research Council (EPSRC). Trevor Bench-Capon and Peter McBurney acknowledge financial support received from the European Commission's Information Society Technologies (IST) programme, through Project ASPIC (IST-FP6-002307).

\section{Notes}

1 Note that use of the word "program" in this context is not due to our computational perspective, but is in fact the usage of political philosophers (Habermas 1998, p. 239).

2 Rousseau gave procedures neither for identifying the general will, nor for reconciling competing interpretations of it.

\section{References}

Arrow, K. J. (1951). Social Choice and Individual Values. Wiley: New York.

Bench-Capon, T. J. M. (1998). Specification and Implementation of Toulmin Dialogue Game. In Proceedings of JURIX 98 (JURIX-1998), 5-20, GNI: Nijmegen.

Bessette, J. (1980). Deliberative Democracy: The Majority Principle in Republican Government: In Goldwin, R. A. and Schambra, W. A. (eds. How Democratic is the Constitution?. American Enterprise Institute: 102-116, Washington, DC, USA.

Bohman, J. and Rehg, W. Introduction, ix-xxx. In (Bohman and Rehg 1997).

Bohman, J. and Rehg, W. (eds.) (1997). Deliberative Democracy: Essays on Reason and Politics. MIT Press: Cambridge, MA, USA.

Downs, A. (1957). An Economic Theory of Democracy. Harper and Row: New York, NY, USA.

Fiorino, D. J. (1989). Environmental Risk and Democratic Process: A Critical Review, Columbia Journal of Environmental Law 14: 501-547. 
Forester, J. (1999). The Deliberative Practitioner: Encouraging Participatory Planning Processes. MIT Press: Cambridge, MA, USA.

Gordon, T. F. and Karacapilidis, N. I. (1997). The Zeno Argumentation Framework. In Proceedings of 6th International Conference on AI and Law (ICAIL-2003), 10-18, ACM Press: New York.

Gordon, T. F. and Richter, G. (2002). Discourse Support Systems for Deliberative Democracy: In Traunmüller, R. and Lenk, K. (eds. EGOV 2002, Lecture Notes in Computer Science. 2456 Springer: 238-255, Berlin, Germany.

Greenwood, K. M., Bench-Capon, T. J. M. and McBurney, P. (2003). Structuring Dialogue between the People and their Representatives: In Traunmüller, R. (ed.), Electronic Government (EGOV 2003), Lecture Notes in Computer Science. 2739 Springer: 55-62, Berlin.

Greenwood, K. M., Bench-Capon, T. J. M. and McBurney, P. (2003b). Towards a Computational Account of Persuasion in law. In Proceedings of 9th International Conference on AI and Law (ICAIL-2003), 22-31, ACM Press: New York.

Habermas, J. (1998). In Cronin, C. and De Greiff P. (eds.), The Inclusion of the Other: Studies in Political Theory, MIT Press: Cambridge, MA, USA.

Lührs, R., Albrecht, S., Lübcke, M. and Hohberg, B. (2003). How to Grow? Online Consultation about Growth in the City of Hamburg: Methods, Techniques, Success Factors: In Traunmüller, R. (ed.), Electronic Government (EGOV 2003), Lecture Notes in Computer Science. 2739 Springer: 79-84, Berlin, Germany.

McBurney, P. and Parsons, S. (2001). Intelligent Systems to Support Deliberative Democracy in Environmental Regulation, Information and Communications Technology Law 10(1): 3343.

McBurney, P. and Parsons, S. (2004). Engineering Democracy in Open Agent Systems: In Omicini, A., Petta, P. and Pitt, J. (eds. Engineering Societies in the Agents World IV, Lecture Notes in Artificial Intelligence. 3071 Springer: 66-80, Berlin, Germany.

Michelman, F. I. (1989). Conceptions of Democracy in American Constitutional Argument: The Case of Pornography Regulation, Tennessee Law Review 56: 291-319.

Rousseau, J. J. (1994). The Social Contract, Oxford University Press: Oxford, UK. Published 1762. Translated by Christopher Betts, in a volume entitled: Discourse on Political Economy and The Social Contract.

Sæbø, Ø. and Nilsen, H. (2004). The Support for Different Democracy Models by the Use of a Web based Discussion Board: In Traunmüller, R. (eds. Electronic Government (EGOV 2004), Lecture Notes in Computer Science. 3183 Springer: 23-26, Berlin.

Schumpeter, J. (1950). Capitalism, Socialism, and Democracy, Harper: New York, USA, third edition, 1950. First edition 1942.

Webler, T., Tuler, S. and Krueger, R. (2001). What is a Good Public Participation Process? Five Perspectives from the Public, Environmental Management 27(3): 435-450. 